\title{
Correction to: A manual-based family intervention for families living with the consequences of traumatic injury to the brain or spinal cord: a study protocol of a randomized controlled trial
}

Pernille Langer Soendergaard ${ }^{1,2^{*}}$, Mia Moth Wolffbrandt ${ }^{1}$, Fin Biering-Sørensen ${ }^{3,4}$, Malin Nordin ${ }^{5}$, Trine Schow ${ }^{6}$, Juan Carlos Arango-Lasprilla, ${ }^{7,8}$ and Anne Norup ${ }^{1,2}$

\section{Correction to: Trials (2019) 20:646}

https://doi.org/10.1186/s13063-019-3794-5

After publication of our article [1] we were notified that a few duplicate sentences were included on page 7 of the manuscript.

The original article has been corrected.

\section{Author details}

'Department of Neurorehabilitation, TBI Unit, Rigshospitalet, Kettegaard Allé 30, 2650 Hvidovre, Denmark. ${ }^{2}$ Department of Psychology, University of Southern Denmark, Campusvej 55, 5230 Odense, Denmark. ${ }^{3}$ Clinic for Spinal Cord Injuries, Rigshospitalet, University of Copenhagen, Havnevej 25, 3100 Hornbæk, Denmark. Institute for Clinical Medicine, University of Copenhagen, Blegdamsvej 3B, 2200 Copenhagen, Denmark. ${ }^{5}$ Department of Neurosurgery, Karolinska University Hospital, Eugeniavägen 3, 17176 Stockholm, Sweden. ${ }^{6}$ Research and Development, Brain Injury Center BOMI,

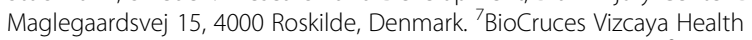
Research Institute, Cruces University Hospital, Barakaldo, Spain. ${ }^{8}$ IKERBASQUE Basque Foundation for Science, Bilbao, Spain. 'Department of Cell Biology, University of the Basque Country (UPV/EHU), Leioa, Spain.

Published online: 27 December 2019

\section{Reference}

1. Soendergaard $\mathrm{PL}$, et al. A manual-based family intervention for families

living with the consequences of traumatic injury to the brain or spinal cord: a study protocol of a randomized controlled trial. Trials. 2019;20:646. https:// doi.org/10.1186/s13063-019-3794-5.

\footnotetext{
The original article can be found online at https://doi.org/10.1186/s13063019-3794-5

${ }^{*}$ Correspondence: Pernille.langer.soendergaard@regionh.dk

1 Department of Neurorehabilitation, TBI Unit, Rigshospitalet, Kettegaard Allé 30, 2650 Hvidovre, Denmark

${ }^{2}$ Department of Psychology, University of Southern Denmark, Campusvej 55, 5230 Odense, Denmark

Full list of author information is available at the end of the article
}

(c) The Author(s). 2019 Open Access This article is distributed under the terms of the Creative Commons Attribution 4.0 International License (http://creativecommons.org/licenses/by/4.0/), which permits unrestricted use, distribution, and reproduction in any medium, provided you give appropriate credit to the original author(s) and the source, provide a link to the Creative Commons license, and indicate if changes were made. The Creative Commons Public Domain Dedication waiver (http://creativecommons.org/publicdomain/zero/1.0/) applies to the data made available in this article, unless otherwise stated. 